\title{
ISAAC PAVLOVSKI CUENTA UN EPISODIO CURIOSO DE LA VIDA DE EMILIA PARDO BAZÁN
}

\author{
por \\ CRISTINA PATIÑO EIRÍN
}

\begin{abstract}
Dentro de la rica personalidad de la Condesa de Pardo Bazán sobresale como uno de los aspectos más valiosos el de su labor difusora de la literatura rusa en España. Cabe decir que a doña Emilia debemos la introducción y propagación, en el panorama literario español del siglo XIX, de los novelistas clásicos rusos, a los que accedió a través de traducciones francesas. Todavía está por investigar la recepción de este ancho y fecundo caudal literario en el universo de la España decimonónica ${ }^{1}$, pero es evidente su repercusión especialmente a partir del último tercio del XIX.

$\mathrm{Si}$ es fácil constatar, de un modo aproximado, el conocimiento de la llamada "espiritualidad rusa" y la presencia en la novela del momento de su peculiar manera de sentir, resulta más arduo averiguar si en la Rusia de esa época existía también algún tipo de interés por la literatura española de fin de siglo. En este sentido el Profesor José Manuel González Herrán ha subrayado la importancia de la obra de un interesante periodista
\end{abstract}

\footnotetext{
${ }^{1}$ Es interesante en este sentido el artículo de Carlos VAÍlLO, reseña de la obra de V. Y. Bagno Emilia Pardo Bazán i ruskaya literatura y Ispanii (E.P.B. y la literatura rusa en España), en Insula, núms. 488-489, 1987.
}

"CUADERNOS DE ESTUDIOS GALLEGOS", Tomo XXXIX, Fascículo 104, Santiago 1991. 
ruso que visitó nuestro país en 1884 y $1885^{2}$. Este viajero hispanista, llamado Isaac Pavlovski, conoció de cerca a muchos de los más importantes escritores españoles del momento. Sus visitas a España cuajaron en un libro, todavía no traducido al español, cuyo título es Bosquejos de la España contemporánea. Data del año 1889 y en él se da cumplida noticia de las impresiones que la variopinta sociedad española de entonces despierta en un viajero procedente de la Rusia de los zares.

$\mathrm{El}$ aspecto de este libro que aquí nos interesa es aquel que se refiere a un episodio de la vida de Pardo Bazán. Dada la primicia del texto ${ }^{3}$, que yo misma he traducido del ruso, resulta obligada la cita por extenso. Su novedad disculpa de algún modo esa longitud.

Comienza Isaac Pavlovski refiriéndose al momento en que vio por primera vez a la novelista coruñesa:

«Conocí a la Condesa de Pardo Bazán en París. Diariamente, mediado ya el invierno, en los salones parisinos y en los círculos literarios aparecía su original figura. Muy morena, regordeta, con un bello perfil romano y con los quevedos sobre la nariz, incorregible disputadora y habladora, se dejaba caer en el salón de Madame Adam o en el de los "devoradores de popes" de Madame Gagnor, en las "premières", en los aburridos bailes de ministros o del Presidente de la República, en las reuniones de jóvenes literatos, en las mañanas de Goncourt o en las veladas íntimas del agente de don Carlos, el Conde de Aguirre».

Tras esta descripción pasa a referir su poderosa vocación literaria:

«Los días de entre semana, hasta las cuatro, encontraréis invariablemente a doña Emilia en la gran sala de la BIblioteca Nacional, enfrascada en la lectura de enormes infolios. La señora Pardo Bazán es

${ }^{2}$ GONZÁLEZ HERRÁN, José Manuel, “Un nihilista ruso en la España de la Restauración (Isaac Pavlovski y sus relaciones con Galdós, Oller, Pardo Bazán, Pereda)”, XXIII, 1988, pp. 83-105.

${ }^{3}$ Con posterioridad a la redacción de estas líneas he sabido, por mediación verbal del profesor González Herrán, que Maurice Hemingway conoce la existencia de una carta enviada por Pardo Bazán a Pérez Galdós en la que la escritora coruñesa le cuenta el episodio novelesco que nos ocupa. Esta misiva, con fecha del 10 de julio de 1886, vendría a subrayar el valor que doña Emilia atribuía a esta anécdota. La carta en cuestión se encuentra en Canarias y sigue, por el momento, inédita. Como señala el Profesor Hemingway en su artículo "Pardo Bazán and the Rival Claims of Religion and Art" (BHS, LXVI, 1989), de ella se desprende que la novelista tenía la intención de narrar su aventura carlista bajo el título de Mi Episodio Nacional, proyecto que nunca realizaría.

"CUADERNOS DE ESTUDIOS GALLEGOS", Tomo XXXIX, Fascículo 104, Santiago 1991. 
en realidad novelista, pero en los ratos libres se transforma en crítico, en adiestradora de temores y miedos en el mundo de la literatura española. Últimamente a estas ocupaciones ha agregado aun otro arduo trabajo, que le llevará no menos de diez años; está escribiendo la historia de la literatura española en diez voluminosos tomos. Sin duda alguna la señora la llevará hasta el final sin contratiempos, ya que cuenta treinta y tres años y goza de una energía verdaderamente de hierro» ${ }^{4}$.

Constatamos, pues, que el hispanista ruso ha sabido captar los relieves de la personalidad de la escritora. Entre los múltiples proyectos de la autora de La Madre Naturaleza menciona uno de índole histórico-crítica, semejante al que don Marcelino Menéndez Pelayo se traía entre manos, y que no llegó nunca a culminar.

Con gran acierto, Isaac Pavlovski se refiere seguidamente al carácter europeo de la erudición pardobaziana así como a su vertiente feminista. Comenta con gran lujo de detalles la precariedad en que vive la mujer española y resalta, de este modo, la valía de la autora de La Tribuna:

«En España a la mujer le resulta más difícil que en otras partes ocupar un lugar destacado en el mundo literario. En general, las españolas reciben muy mala instrucción, para ser más exactos, no la tienen en absoluto. Aparte de esto, como en todos los países donde la vida se concentra en la calle y en el café, la mujer española administra su vida aislada, raramente participa en sociedad y su libertad se expresa en el momento en que habla por las tardes desde el balcón con su "novio" o baila en las tertulias. La intervención en la vida social y en la literatura tropieza en España con la indignación y las risas ruines. Incluso en una celebridad casi europea como la recientemente fallecida Fernán Caballero, merced a estas circunstancias, sólo pudo comenzar su actividad literaria en la edad de la vejez, bajo la protección de pseudónimo y del reinado personal y reforzado de Isabel (...). La señora Pardo Bazán ha roto afortunadamente todas estas trabas» ${ }^{5}$.

Con gran pormenor destaca el periodista originario de Taganrog lo granado del linaje de doña Emilia:

«Hija de un aristócrata patrimonial de Galicia, republicano acérrimo y hombre instruído, se crió en la vetusta casa solariega, en una aldea cercana a La Coruña, y desde la edad de quince años empezó a leer toda su enorme biblioteca ${ }^{6}$.

${ }^{4}$ PAVLOVSKI, Isaac, Bosquejos de la España contemporánea, San Petersburgo, 1889 , p. 184.

${ }^{5}$ y ${ }^{6}$ PAVLOVSKI: 1889 , pp. 174 y 175.

"CUADERNOS DE ESTUdIOS GALLEGOS", Tomo XXXIX, Fascículo 104, Santiago 1991. 
Seguidamente Pavlovski narra un episodio verdaderamente sorprendente para cualquier conocedor de la escritora gallega. Lo novedoso y peregrino de esta extraña historia merece el que la reproduzcamos en su integridad, sobre todo si tenemos en cuenta que ninguno de los biógrafos de la condesa, ni siquiera Carmen Bravo-Villasante - una de las máximas conocedoras de la vida de nuestra autora, en su libro Vida y obra de Emilia Pardo Bazán, hace referencia a esta anécdota. Pavlovski aprovecha la facundia novelesca de la autora de Los Pazos de Ulloa para contarnos así un episodio que quizá era bien conocido entre los amigos de la novelista:

«A los quince años se casó con el señor gallego de Quiroga y poco tiempo después esta hija de republicano se lanzó al remolino de la sublevación carlista. Rápidamente adquirió tal influjo en este partido de campesinos y sacerdotes que con vehemencia creyó en la agitación, que la hacía una de sus jefes no sólo en Galicia, sino también en toda España. Don Carlos le confió la adquisición de 30.000 fusiles en Londres, y ella, arriesgando la cabeza en las zonas de bandidos y del ejército del Gobierno atravesó de noche la frontera portuguesa para cumplir su misión. Tenía en esos momentos en el cinturón varios cientos de miles de francos en onzas de oro, el peso de los cuales dio a su pecho la apariencia de una espaciosa "herida". Pero por la "santa causa" ¡sufrir es halagador!...

Desde Londres vía París, donde entonces se daba buena vida el pretendiente al trono español, regresó a casa la joven, que no había pagado con su cabeza la fidelidad a las ideas carlistas; le esperaba ya preparada la celda en la cárcel coruñesa pero las autoridades militares se reunieron para fusilarla. Un amigo de la casa, el Gobernador de La Coruña, conocido suyo de la infancia, le enviaba diariamente a su ayudante con esquelas "rogando a Emilia se escondiese, de lo contrario él se vería obligado a arrestarla y a no responder de las consecuencias". Pero la joven entusiasta obstinadamente contestaba cada vez: "que don Francisco cumpla con su deber, yo ejecutaré el mío". Al final, sin embargo, el Gobierno no se atrevió a adoptar medidas rigurosas en relación con la hija del firme republicano y, de grado o por fuerza, hubo de cerrar los ojos a regañadientes ante la actividad de agitación» ${ }^{7}$.

Es realmente un episodio asombroso e inédito ${ }^{8}$. De ser cierto, y así lo considera Pavlovski, añadiría un punto más de intrepidez y audacia a la

${ }^{7}$ PAVLOVSKI: 1889, pp. 175 y 176.

8 Ya Robert E. Osborne recogía en su libro Emilia Pardo Bazán. Su vida y sus obras (1964) algunas consideraciones en torno al carlismo de doña Emilia y mencio- 
vida de doña Emilia.

A continuación, Isaac Pavlovski nos cuenta el proceso literario seguido por la que considera su amiga y además "autora de colosal erudición, transparencia y fuerza de pensamiento lejos de la mediocridad" . Pero este apartado, sin duda de gran interés, quedará referido en otra ocasión.

naba, como advierte M. Hemingway, el episodio del que nos ocupamos en este artículo. Osborne dice lo siguiente: "Escribe doña Emilia en Polémicas y estudios literarios: "Adhesión profesé yo al duque de Madrid (Don Carlos) en años juveniles hasta el punto de arriesgar la vida por su causa - cosa que por haberla verificado tantos españoles ni nombrarse merece- y no le había visto jamás". Boris de Tannenberg dice en L'Espagne littéraire: "Mais les excès révolutionnaires la jetèrent dans l'extrême réaction carliste. Je l'ai entendue conter bien de fois qu'elle conspire activement et alla acheter des fusils en Angleterre. Depuis lors, l'évolution de ses idées l'a ramenée au libéralisme". El gran peruano Ricardo Palma comenta en sus Recuerdos de España: "Realmente, doña Emilia, en el carlismo, era una planta exótica, como lo sería mañana en el campo de los republicanos. Para carlista le faltan fanatismo religioso y amor al pasado con todos sus errores y ñoñerías; y para republicana le falta la fe de la creencia en el dogma democrático". En la página 204 dice: "Jaime, ahijado de bautismo de don Carlos de Borbón, abogado entusiasta por la causa de su padrino, apoyándolo dos o tres de los presentes. Yo oía impasible los encontrados juicios cuando doña Emilia, que en un tiempo fue carlista y hasta desempeñó en Inglaterra misión de servicio de la causa, etc.".

Como señala M. Hemingway en el artículo arriba mencionado, Pardo Bazán fue una activa partidaria del carlismo en los años 1870. Posteriormente, a partir de 1880 , la autora confesará que "el problema del partido carlista es que lo que constituye su fuerza constituye también su impotencia. Inmutable, negándose a arrollar ni una punta de su bandera (...) vive de su propia cadavérica rigidez". En diciembre de 1888 escribe a Oller: "Los carlistas representan un aspecto de España: lástima grande que ese vigor y esa comprimida actividad no la gastan en algo beneficioso para nuestra pobre patria, en vez de malgastarla en estériles y baldías escaramuzas y en escandalosas y continuas reyertas" (recogido por M. Hemingway en el artículo citado).

${ }^{9}$ PAVLOVSKI: 1889, p. 173.

"CUADERNOS DE ESTUDIOS GALLEGOS", Tomo XXXIX, Fascículo 104, Santiago 1991 